\title{
Functional Difficulties and Inequalities Through a Static Lens
}

\begin{abstract}
This chapter is about the association between disability and inequalities. Results from both descriptive statistics and regressions indicate that functional difficulties have significant and large associations with both individual and household deprivations in Ethiopia, Malawi, Tanzania, and Uganda. This is found through an indicator-by-indicator analysis as well as through an assessment of multidimensional poverty. There are four wellbeing dimensions for which functional difficulties were systematically associated with deprivations in the four countries: education, morbidity, employment, and economic security. Some persons with functional difficulties do achieve levels of wellbeing comparable to persons with no difficulty. The association between functional difficulties and deprivations was found for both severe and moderate functional difficulties, although it was typically larger and more often significant for the former.
\end{abstract}

Keywords Disability - Poverty - Multidimensional poverty - Gender • Aging - Africa

JEL Il $\cdot \mathrm{I} 3 \cdot \mathrm{O} 15$

S. Mitra, Disability, Health and Human Development, Palgrave Studies in Disability and International Development, DOI 10.1057/978-1-137-53638-9_5 
This chapter investigates the association between functional difficulties on the one hand, and different deprivations, on the other. For Ethiopia, Malawi, Uganda, and Tanzania, it uses cross-sectional LSMS data and thus draws a static snapshot of this association. Framing this question within the human development model, the objective is to assess the association between functional difficulties and deprivations measured in terms of educational attainment, morbidity, employment, material wellbeing, economic security and through the experience of multidimensional poverty.

\subsection{Literature on Inequalities Associated With DisabiLITy}

Globally, the evidence on the wellbeing inequalities associated with disability is limited, although the situation greatly differs between HICs and LMICs. Most of the evidence pertains to HICs. Overall, in HICs, the evidence suggests that persons with disabilities have lower educational attainment and experience lower employment rates, lower wages when employed, and are more likely to be income poor (Brucker et al. 2015; Grammenos 2013). They are also more likely to be chronically poor (She and Livermore 2009). In LMICs, there is very limited empirical research on disability and poverty or deprivations in general (Groce et al. 2011; Grech 2015; Banks and Polack 2014). The peer-reviewed literature, while still small, has recently grown. The literature review below is limited to deprivations in dimensions of wellbeing later analyzed in this chapter and to peer reviewed papers published since 2000. ${ }^{\mathrm{I}}$ The qualitative evidence that gives space to the voices and perceptions of persons with disabilities is beyond the scope of this review. ${ }^{2}$

\subsubsection{Material Wellbeing}

This section starts with material wellbeing, typically measured through consumption expenditures, assets, and living conditions. There has not been consistent evidence of material deprivations for households with disabilities relative to other households. Hoogeveen (2005) (Uganda) and Mont and Cuong (2011) (Vietnam) find that households with disabilities have lower expenditures than households without, but Rischewski et al. (2008) (Rwanda) does not. A cross-country study of LMICs (Filmer 2008) finds that in eight out of 12 countries, disability in adulthood is associated with a higher probability of being in poverty, 
where poverty refers to belonging to the lowest two quintiles in terms of household expenditures or asset ownership. Another cross-country study (Mitra et al. 2013) finds a significant difference in household per capita expenditures across disability status in only three out of 15 LMICs.

There are, however, challenges in using household expenditures to assess the wellbeing of households with disabilities, as they may reflect additional expenditures associated with a disability (NDSD 2015). These expenditures may relate to general items that any household may need (e.g., healthcare, food) as well as to disability-specific items (e.g., assistive devices, rehabilitation), although this is perhaps less of a concern in the LICs under consideration in this study where disability-specific goods and services may not be available. Having similar or higher expenditures at the household level across disability status does not necessarily imply that the standard of living is similar. This empirical concern regarding the use of household expenditures is related to the conversion function and its particular relevance to disability, as discussed earlier in Chapter 2.

With respect to asset ownership, several studies show that households with disabilities have fewer assets and worse living conditions compared to other households. ${ }^{3}$ However, Eide et al. (2003a) and Trani and Loeb (2010) find no significant difference in Zimbabwe and Afghanistan/ Zambia, respectively. Mitra et al. (2013) find a significant difference in the rate of asset deprivation in only four of 15 LMICs.

\subsubsection{Educational Attainment}

There is extensive and consistent evidence that adults with disabilities have lower educational attainment in a number of LMICs. ${ }^{4}$ This association consistently found among adults may result from lower school attendance among children with disabilities (Filmer 2008; Mizunoya et al. 2016), but may also be due to more frequent onsets among adults with limited educational attainment because they are more exposed to malnutrition, lack of access to healthcare, and risky working conditions.

\subsubsection{Employment}

How disability may impact employment is an empirical question, and realities in LMICs may differ from HICs. In an agrarian economy, as is often the case in LICs, many jobs are in the primary sector (agriculture, forestry, mining) and may involve heavy manual labor, which people with 
physical difficulties may not be able to do. People with hearing or cognition difficulties, on the other hand, may not experience barriers to physical labor. The effect of disability on employment will also depend on the workplace, its accessibility, available accommodations and transport, and whether there is discrimination that might prevent access to employment and/or might lead to lower wages (Baldwin and Johnson 2005; Mitra and Sambamoorthi 2008). The policy context is also relevant; for instance, vocational rehabilitation, disability insurance, or social assistance programs could facilitate, limit or not affect access to employment for persons with disabilities depending on how they are designed and implemented. In some LMICs (e.g., South Africa), social protection benefits have been introduced to provide financial support to persons with disabilities.

Several studies in LMICs find that persons with disabilities are less likely to be employed. ${ }^{5}$ In a study of 15 countries, Mizunoya and Mitra (2013) have results that are somewhat mixed with a significant disability gap in employment rates in nine countries out of 15. In these nine countries with a disability gap, the size of the gap varies greatly across countries.

Finally, it should be noted that not working may not be an option. So people may be begging or selling small items on the roadside earning very little but working. Hence, the type of employment needs to be considered. In most LMICs, a large majority are in the informal sector. Some studies have shown that persons with disabilities are disproportionately more likely to be working in the informal sector than persons without disabilities (e.g., Adioetomo et al. 2014; Mizunoya and Mitra 2013).

\subsubsection{Morbidity and Healthcave Expenditures}

Disability is associated with a wide range of health conditions (WHOWorld Bank 2011); some of which may result in morbidity and high healthcare needs. These may lead to higher health expenditures. Trani and Loeb (2010) also show that on average, 'persons with severe or very severe disabilities spent 1.3 times more on healthcare than nondisabled respondents' (p. 36). Mitra et al. (2013) show that households with disabilities have a higher ratio of medical to total expenditures in nine out of 15 countries while WHO-World Bank (2011) finds that persons with disabilities are more likely to experience catastrophic health expenditures. 
Overall, in LMICs, there is not a consistent overall pattern of evidence on disability and deprivations. The evidence thus far points toward individuals with disabilities being worse off in terms of educational attainment, morbidity, and health expenditures, while in terms of employment and household material wellbeing, the evidence is more mixed.

\subsubsection{Multidimensional Poverty}

The literature review so far considered inequalities in one dimension of wellbeing at a time. Recently, several studies have found that disability is associated with a higher likelihood of experiencing multidimensional poverty (Mitra et al. 2013; Trani and Cunning 2013; Trani et al 2015, 2016). These deprivations can be in terms of employment, health, education, material wellbeing, social participation or psychological wellbeing. This growing literature has provided consistent evidence that in LMICs, disability is correlated with the experience of multidimensional poverty while the very nature of deprivations may vary across countries. For instance, it could be in terms of employment and healthcare access in one country, but in terms of educational attainment and living conditions in another.

This consistent association between disability and multidimensional poverty comes in contrast to the more mixed evidence on disability and material wellbeing. This literature, however, remains small and so far separate from the growing general research on multidimensional poverty. The MPI offers a measure of the experience of simultaneous deprivations at the household level and is increasingly used in policy and research (Alkire and Santos 2014). It is yet to present separate results for households with disabilities.

\subsubsection{Overview}

Deriving any definitive conclusion on inequalities across disability status is problematic in this literature with varying measures for disability, wellbeing indicators, data sources, and methodologies. First, studies use different methods: some studies only present means and frequency counts of economic indicators across disability status (e.g., Hoogeveen 2005), while other studies resort to multivariate analysis using a variety of empirical strategies which can be difficult to compare. ${ }^{6}$ Some studies measure disability through functional difficulties (e.g., Mont and Cuong 2011), while others use broad activity limitations (e.g., Mitra 2008). Several of these 
studies (Mitra et al. 2013; Mizunoya and Mitra 2013; WHO-World Bank 2011) rely on the World Health Survey (WHS) that was designed to collect a detailed health and disability profile of individuals but provides only summary measures of economic wellbeing, for instance, on employment and household expenditures. Besides, not every individual in a household in the WHS was interviewed, only one individual per household. Hence, differences across disability status may be underestimated for household wellbeing indicators. Finally and more importantly, results vary across wellbeing dimensions, making the evidence mixed. It could be read in different ways. Someone relying on traditional poverty measures based on consumption expenditures or asset ownership data will not find any consistent significant association between disability and poverty. Someone relying on multidimensional poverty measures will. This is surprising given the consistent evidence found in HICs, whatever the measure of poverty.

As a result, despite a growing body of research on disability-related inequalities in LMICs, more work is needed with internationally comparable and tested disability measures and detailed economic indicators suitable to the LMIC context to understand disability and inequalities. Research is particularly needed in the context of LICs. Mizunoya and Mitra (2013) note that the six countries in this study that do not have a disability gap in employment are LICs, while only two of the nine countries with a disability gap (Bangladesh and Burkina Faso) are in the lowincome category. This is consistent with the results on multidimensional poverty in Mitra et al. (2013). In both studies, the authors hypothesize that economic inequalities associated with disability may be more common in middle-income countries compared to LICs because as countries develop, there may be growing barriers to employment and economic activities for persons with disabilities. It could also be that disability is associated with premature mortality in LICs, more so than in middleincome countries, which would drive down the association between disability and economic deprivations. This chapter aims to fill some of these gaps in the literature by offering evidence for Ethiopia, Malawi, Tanzania, and Uganda.

\subsection{Methodology}

This Chapter presents for several indicators of wellbeing at the individual and household levels bivariate and multivariate analyses to investigate the association between functional difficulties and wellbeing in a 
number of domains. For this analysis, as described in Chapter 3, the following datasets are used: the 2010/11 Malawi Third Integrated Household Survey, the 2010/11 Tanzania National Panel Survey, the 2011/12 Ethiopia Rural Socioeconomic Survey and the 2009/10 Uganda National Panel Survey. The measures of moderate or severe functional difficulties and the functional score are as explained earlier in Chapter 3.

\subsubsection{Wellbeing Indicators}

The household and individual wellbeing indicators analyzed in this chapter are presented in Table 5.1. As explained in Chapter 3, they were chosen based on a review of the datasets and guidance from Stiglitz et al. (2009) for a list of dimensions of wellbeing. In the four countries, an index of assets and living conditions is used (Filmer and Pritchett 2001). Assets include ownership of a bike, a car, a refrigerator, a fixed-line telephone, a cell phone, a television set, and a computer. Living condition variables include building quality (high-quality floor and wall materials), water source (from pipes, from protected wells, and from unprotected sources), type of toilet (flush, latrine, other/none), and use of a gas or electric cooking stove. ${ }^{7}$ The index is normalized to range from zero to 100 (Table 5.1).

For Malawi, Tanzania, and Uganda, a comprehensive range of annual expenditure variables are analyzed: total, total nonhealth, health, ${ }^{8}$ and education. ${ }^{9}$ In Ethiopia, expenditures were collected only on food items, so these expenditures-based indicators cannot be used. The monetary poverty status of the household is determined using the international $\$ 1.90$ poverty line. Detailed income data from earned and unearned sources is not available in the four countries, but data on income received from social protection transfers is. Social Protection transfers include assistance received by the household from government or nongovernment institutions (such as church). Two measures of economic insecurity are also used. One covers food insecurity; it measures whether the household faced a situation where it did not have enough food. The other one measures if the household has experienced a shock recently.

Several issues should be noted with regard to using household (nonhealth) expenditures as a dimension of economic wellbeing in the context of this study. First, as pointed earlier, if poverty is measured 
Table 5.1 Aspects of wellbeing and indicators

\begin{tabular}{|c|c|}
\hline Wellbeing & Indicators \\
\hline \multicolumn{2}{|l|}{ Household level: } \\
\hline Assets/Living conditions & Asset index ${ }^{1}$ \\
\hline \multirow[t]{5}{*}{ Household Consumption } & Household's daily per capita expenditures (PCE) is under \\
\hline & $\begin{array}{l}\text { Total expenditures: Annual expenditures for the household } \\
\text { and in local currency }\end{array}$ \\
\hline & $\begin{array}{l}\text { Total expenditures (nonhealth): Annual expenditures for the } \\
\text { household and in local currency }\end{array}$ \\
\hline & $\begin{array}{l}\text { Health expenditures: Annual expenditures for the household } \\
\text { and in local currency }\end{array}$ \\
\hline & $\begin{array}{l}\text { Education expenditures: Annual expenditures for the house- } \\
\text { hold and in local currency }\end{array}$ \\
\hline Income & $\begin{array}{l}\text { Social protection transfers for the household in local currency } \\
\text { per year }\end{array}$ \\
\hline Food insecurity & $\begin{array}{l}\text { In the past } 12 \text { months, household respondent faced with a } \\
\text { situation when did not have enough food to feed the house- } \\
\text { hold. }\end{array}$ \\
\hline Shocks & Household experienced a shock recently ${ }^{3}$ \\
\hline \multicolumn{2}{|l|}{ Individual level: } \\
\hline Educational attainment & Ever attended school \\
\hline Morbidity & Sick or injured recently ${ }^{4}$ \\
\hline \multirow{3}{*}{ Work status } & Worked in the past week ${ }^{5}$ \\
\hline & Hours worked 6 \\
\hline & $\begin{array}{l}\text { Type of work (family farm, family business, wage work, other } \\
\text { work) }\end{array}$ \\
\hline
\end{tabular}

Notes ${ }^{1}$ See text for details on the asset index

${ }^{2}$ Social protection transfers refer to assistance received by the household from government or nongovernment (such as church) institutions

${ }^{3}$ Each household was asked about shocks experienced in the past 12 months in Ethiopia, Malawi and Uganda and in the past 5 years in Tanzania. For each country, the question was asked for a list of under 20 types of shocks (e.g. drought or floods, livestock died or stoken, loss of land). A variable was constructed to indicate that a household experienced at least one shock

${ }^{4}$ For Malawi and Uganda, the question refers to an 'illness or injury' in the past 2 weeks and 30 days respectively. For Ethiopia, the question refers to 'a health problem' in the past 2 months. For Tanzania only, the question asks if the person visited a healthcare provider in the last 4 weeks: there is no question on recent health problem or illness/injury

${ }^{5}$ Work indicates if an individual worked in past 7 days or did not work in past 7 days but has a job to return to. Work can be of any type for pay, profit, barter or home use and also includes apprenticeships ${ }^{6}$ Hours worked refer to hours worked in the past week among individuals who worked in the past week. In all countries but Uganda, individuals were queried about hours worked by type of work (e.g. farm, business). In Uganda, work hours were asked for each day of the past week for the individual's main job and secondary job 
through per capita expenditures (PCE) against a poverty line, the comparison of households with a functional difficulty to other households may be biased due to the conversion factors: households with disabilities may have additional (nonhealth) needs and hence expenditures (e.g., transportation, personal assistance) due to the functional difficulty. Evidence on the additional costs of living with a disability is available only in very few LMICs. ${ }^{10}$ Second, there is the possibility that the intra-household distribution of expenditures is unequal across functional difficulty status. For these two reasons, PCE may not be an accurate indicator of economic disparities across functional difficulty status. In contrast, assets or living conditions, at least the ones included in this study as described earlier, can be, to a larger extent, considered as household common goods, so the issue of intra-household distribution is less likely to arise.

Several individual wellbeing indicators are also assessed. Educational attainment is used with an indicator of whether an individual ever attended school. Morbidity is captured by a question asking persons whether they recently experienced a health problem (illness or injury). However, for Tanzania, the question asks if the person visited a healthcare provider in the last 4 weeks; there is no question on recent health problem or illness/injury. Three labor market outcomes are analyzed: work status, hours worked during the last week, and work type. Work status refers to working in the past week or having a job to return to. Work types include working at a family-owned farm or business, a wage job (working for wage, salary or commission) or some other type of work (unpaid family worker or apprenticeship). For Ethiopia, Malawi, and Tanzania, individuals report hours of work during the past week in their first and second job or by type of job; these hours across jobs are added up to get weekly hours of work. For Uganda, daily hours of work are available for each day of the past week, which are added up.

Overall, and in the context of the human development model of Chapter 2, one kind of health deprivations (functional difficulties) is considered in its association with other deprivations related to education, morbidity, work, material wellbeing, and economic security.

\subsubsection{Multidimensional Poverty}

In addition to an indicator-by-indicator analysis, this study estimates a set of measures of multidimensional poverty developed by Alkire and Foster 
(2011) to investigate the experience of simultaneous deprivations. This is in line with a multidimensional understanding of wellbeing and poverty in the capability approach in general, and in the human development model, in particular. In brief, this method counts deprivations for a set of dimensions that affect an individual at the same time. An individual is considered multidimensionally poor if the number of deprivations of the individual is equal or above a set threshold. Three multidimensional poverty measures are calculated. The poverty headcount $H$ gives the percentage of the population who are multidimensionally poor. The average deprivation share $A$ gives the share of deprivations experienced by the poor out of all of their dimensions. The adjusted headcount ratio $M_{0}$ is the product of $\mathrm{H}$ and $\mathrm{A}$; in other words, it is the headcount ratio adjusted for the intensity of the deprivations experienced by the poor. It is on a continuum from 0 to 1 . Details on the calculation of this set of measures are included in Box 2.

\section{Box 2: The Alkire and Foster (2011) Multidimensional Poverty} Measures

Dimensions are weighted: $w_{j}$ is the weight of dimension $j$. Each individual $i$ has a weighted count of dimensions where that person is deprived $\left(c_{\mathrm{i}}\right)$ across all measured dimensions: $0 \leq c_{\mathrm{i}} \leq d$ where $d$ is the number of dimensions; $c_{i}=\sum_{j=1}^{d} w_{j} c_{i j}$ with $c_{i j}$ a binary variable equal to one if individual $i$ is deprived in dimension $j$, and zero otherwise. Let $q_{\mathrm{i}}$ be a binary variable equal to one if the person is identified as poor, and to zero otherwise. A person is identified as multidimensionally poor if the person's count of deprivations is greater than some specified cutoff $(k)$ :

if $c_{\mathrm{i}} \geq k$, then $q_{\mathrm{i}}=1$

if $c_{\mathrm{i}}<k$, then $q_{\mathrm{i}}=0$

The headcount ratio for a given population is then the number of poor persons $\left(q=\Sigma q_{\mathrm{i}}\right)$ divided by the total population $(n)$ :

$$
H=\frac{q}{n}
$$

To capture the breadth of deprivations experienced by the multidimensionally poor, in other words, the experience of deprivation in several dimensions, the average number of deprivations that a multidimensionally poor person faces is computed. The total number 
of deprivations experienced by multidimensionally poor people $c(k)$ is calculated as follows: $c(k)=\Sigma\left(q_{\mathrm{i}} c_{\mathrm{i}}\right)$ for $\mathrm{i}=1 \ldots \mathrm{n}$. The average deprivation share is the total number of deprivations of the disadvantaged $(c(k))$ divided by the maximum number of deprivations that the deprived could face $(q d)$ :

$$
A=\frac{c(k)}{q d}
$$

The adjusted headcount ratio, $M_{0}$, combines information on the prevalence of multidimensional poverty and its breadth, as the product of the headcount ratio and average deprivation share:

$$
M_{0}=H A=\frac{c(k)}{n d}
$$

It is important to note that this method has a number of limitations. First, the three measures above are a function of the weights allocated arbitrarily to dimensions. Thus, any poverty calculation using this framework is sensitive to the assumptions used in setting weights. Second, this method is sensitive to the selection of dimensions, and there is no guidance on how to select them. Furthermore, this method also requires that a cutoff is set for each dimension/indicator. Deciding on a specific cutoff point is an arbitrary choice, although it can be an informed one. The cutoff across dimensions - the share of dimensions whereby one needs to experience deprivation-also needs to be specified. As noted in Alkire and Foster (2011), setting the cutoff points 'establishes the minimum eligibility criteria for poverty in terms of breadth of deprivation and reflects a judgment regarding the maximally acceptable multiplicity of deprivations' (p. 483). This judgment is based on expert opinion and seems particularly difficult to make in a cross-country study such as this one. Since multidimensional poverty measures require assumptions for the selection of dimensions, weights, and thresholds, these assumptions are described in detail below.

Based on the information available in the datasets above and the guidance of Stiglitz et al. (2009), five dimensions were selected for the calculation of the multidimensional poverty measure as presented in Table 5.2. The five dimensions include three dimensions of individual wellbeing-education, health and personal activities (work)-and two dimensions at the household level material wellbeing and economic 


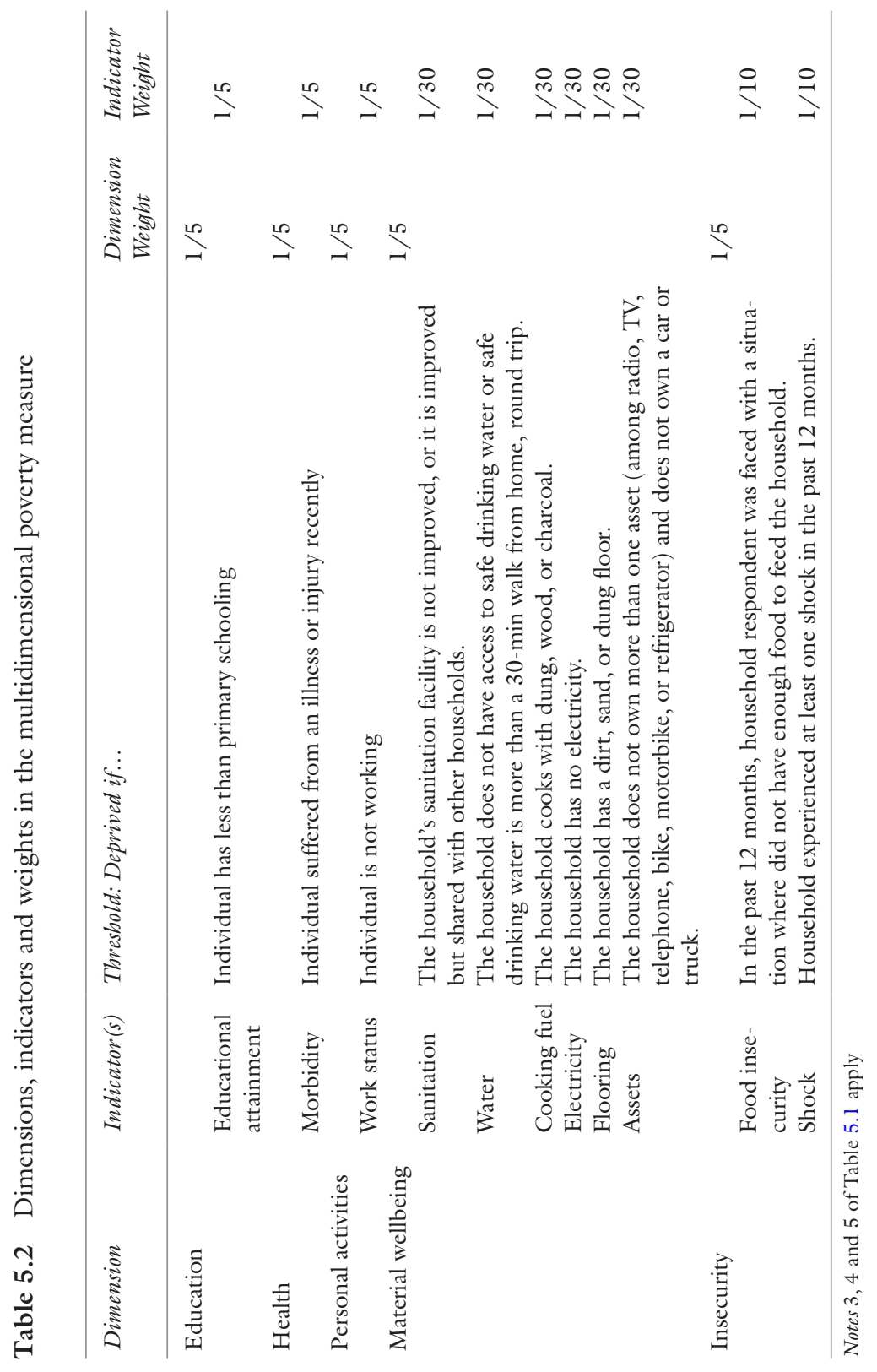


insecurity. In the context of the human development model, the multidimensional poverty measures capture deprivations in terms of functionings, not capabilities. These functionings are related to material wellbeing, economic security, education, morbidity, and work (Fig. 3.1).

The five dimensions are equally weighted and when more than one indicator is used within a dimension, indicators are equally weighted within the dimension. An individual is identified as multidimensionally poor if he or she is deprived in some combination of indicators whose weighted sum exceeds $40 \%$.

The within dimension indicator cutoffs are given in Table 5.2. The selection of indicators and cutoffs was based on a review of the literature measuring the wellbeing dimensions above. As shown in Table 5.2, for household material wellbeing, six indicators are used for assets and living conditions similar to Alkire and Santos (2010), and for household insecurity, two indicators are used: food insecurity and exposure to a shock. ${ }^{11}$ Each of the other dimensions uses only one indicator. The cutoffs for the indicators are as follows: if a person (1) has less than primary schooling; (2) has been sick or injured recently; (3) does not work; (4) The household's sanitation facility is not improved, or it is improved but shared with other households; (5) The household does not have access to safe drinking water or safe drinking water is more than a 30 -min walk from home, roundtrip; (6) The household cooks with dung, wood, or charcoal; (7) The household has no electricity; (8) The household has a dirt, sand, or dung floor; (9) The household does not own more than one asset (among radio, $\mathrm{TV}$, telephone, bike, motorbike, or refrigerator) and does not own a car or truck; (10) In the past 12 months, household respondent faced with a situation when did not have enough food to feed the household; (11) Household experienced at least one shock in the past 12 months. One could argue that some of the thresholds may not capture deprivations. For instance, not working is considered as a deprivation while it may not be, if no or limited decent work is available.

For each of the wellbeing indicators described above, descriptive statistics are presented and include cross-tabulations for each indicator across functional difficulty status. Multivariate regression analysis is also used. 


\subsubsection{Multivariate Analysis}

A linear relationship is specified in which a wellbeing indicator is a function of functional difficulties, individual, household, and community characteristics. For each of the individual wellbeing indicators in Table 5.1 and the multidimensional poverty status described above, a model is used as described in Box 3.

Box 3: Multivariate regression of wellbeing

An OLS or a logistic regression is run in turn for individual wellbeing outcomes as follows:

$$
\text { IndivWellbeing }_{i}=\alpha+\beta_{1} \text { Severe }_{i}+\beta_{2} \text { Moderate }_{i}+\sum_{k} \gamma_{k} x_{i, k}+\varepsilon_{i}
$$

where

- IndivWellbeing $i$ is an individual wellbeing outcome for person $i$ which is in turn: ever attended school, sick or injured in the past month, work and work hours (definitions are in Table 5.1).

- $\alpha$ is the intercept;

- Severe $_{i}$ is a variable equal to 1 if individual $i$ has a severe functional difficulty, 0 otherwise;

- Moderate $_{i}$ is a dummy variable equal to $l$ if individual $i$ has a moderate functional difficulty, 0 otherwise;

- $\beta_{1}$ and $\beta_{2}$ are the coefficients of the functional difficulty variables, to be estimated;

They are the coefficients of interest and their values are reported for each country in Table 5.4.

- $x_{i, k}$ is a set of $\mathrm{k}$ control variables for personal factors (age categories, male), resources and structural factors (being married, being the household head, having a mother with no prior schooling, household size, distance to healthcare). ${ }^{12}$

$-\gamma_{k}$ are the estimated coefficients for the set of $\mathrm{k}$ control variables but are not reported in Table 5.4.

$-\varepsilon_{i}$ is the error term for person $i$. 
In a variant of (5.4), the functional difficulty variables are replaced by the functional score defined earlier in Chapter 3 .

For each of the household wellbeing indicators in Table 5.1, a similar regression model as (5.4) above is estimated:

$$
\text { HHWellbeing }_{i}=\alpha+\beta_{1} \text { Severe }_{i}+\beta_{2} \text { Moderate }_{i}+\sum_{k} \gamma_{k} x_{i, k}+\varepsilon_{i}
$$

where

HHWellbeing $_{i}$ is a household wellbeing outcome for household $\mathrm{i}$ which is in turn is: asset score, below the $\$ 1.90$ per day poverty line, total expenditures, total expenditures (nonhealth), education expenditures, health expenditures, social protection transfers, food insecurity, shocks (definitions are in Table 5.1).

Other symbols are as above for (5.4) except for the set of control variables at the household level (household head's age, marital status, educational attainment, household size, shares of members under age 15 and over age 60 , share of male members ${ }^{13}$ ) and the community level (rural, distance to healthcare services).

It is essential to note that the models above suffer from several important limitations. The first limitation deals with multicollinearity in each of the models. In other words, the control variables are themselves interrelated. As shown in Chapter 4, functional status is related to age, gender, and rural residence. ${ }^{14}$ This, on the other hand, may lead to biased estimates of the coefficient of the functional status variables in the regressions. More importantly, the above models suffer from omitted variable bias. For instance, they do not control for potential confounders, which can affect both wellbeing indicators and functional status. Possible confounders include, for example, violence in the community or household, community services (e.g., health and education facilities, roads), which could affect both functional status and wellbeing indicators. The community control variables (rural residence, distance to healthcare services) in (5.4) and (5.5) above are a very crude way to adjust for these potential structural factors at the community level that may impact household or individual wellbeing as well as functional difficulties. 


\subsection{Results and Discussion}

Results are presented in a set of tables and graphs using the data described in Chapter 3 starting with individual, then household wellbeing and finally multidimensional poverty.

\subsubsection{Individual Wellbeing}

Table 5.3 compares individual outcomes for persons with severe, moderate, or no difficulty for all adults, and then separately for women and men. In all four countries, individuals with moderate or severe functional difficulty have less often ever been to school and are more likely to have been sick or injured recently. The gap in educational attainment across functional difficulty status is large in the four countries. For instance, in Ethiopia, only $15 \%$ and $24 \%$ of persons with severe and moderate difficulties, respectively, have ever attended school compared to $48 \%$ of persons with no difficulty.

The gap in morbidity is large in Ethiopia, Malawi, and Uganda but not in Tanzania. This likely results from the different measures used in Tanzania which is healthcare use and not morbidity.

Individuals with severe difficulties in all four countries are less likely to be working and have fewer work hours than persons with no difficulty. There is a large gap in employment rates in all four countries between persons with severe and no difficulty. The largest is in Tanzania where $53 \%$ of persons with severe difficulties work, compared to $85.4 \%$ among persons without any difficulty. This result of a consistent gap in employment rates for severe functional difficulty stands in contrast to the results in Mizunoya and Mitra (2013) which found a significant gap in only two out of eight LICs using a measure of severe functional difficulty in seeing, moving, concentrating, or selfcare. For moderate difficulty, a significantly lower employment rate is found in Uganda only and significantly lower work hours are found in Ethiopia, Tanzania, and Uganda.

Regarding work type, persons with severe difficulties are less likely to be in wage work and more likely to do household business work in three out of four countries. There is no consistent pattern for farm work with persons with functional difficulties less often in farm work in Ethiopia and Malawi, more often in Tanzania. No significant difference is found in Uganda. 


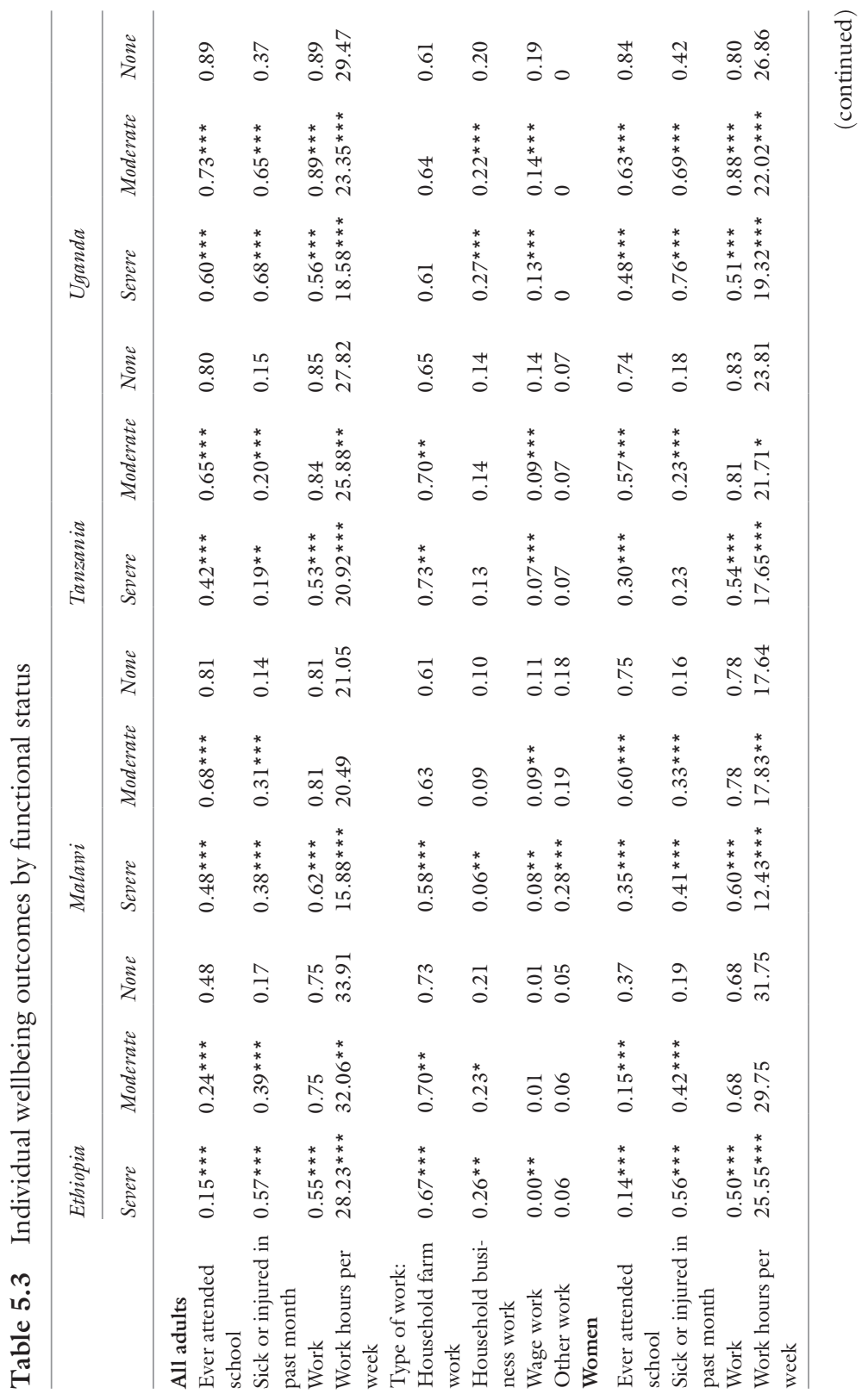




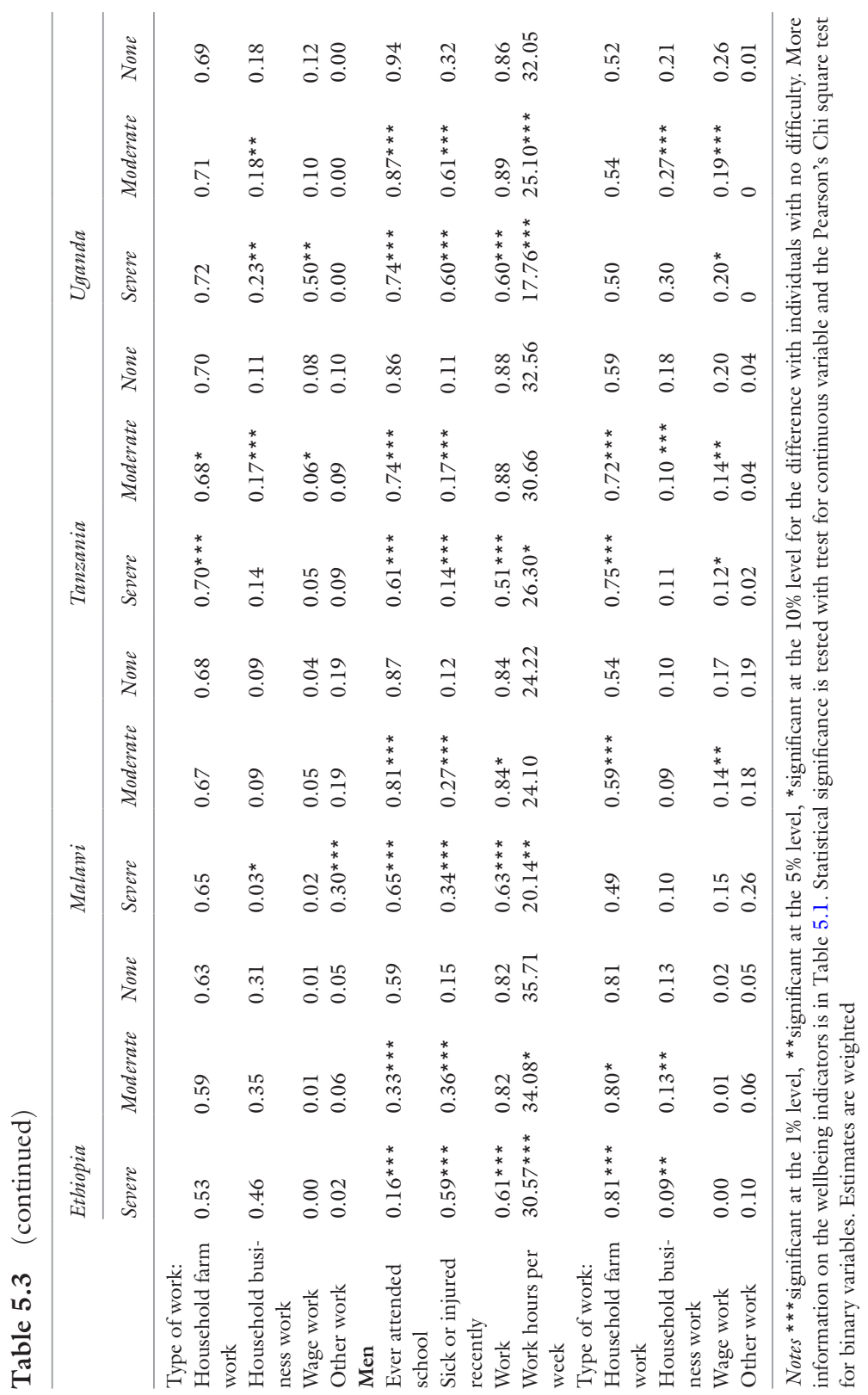




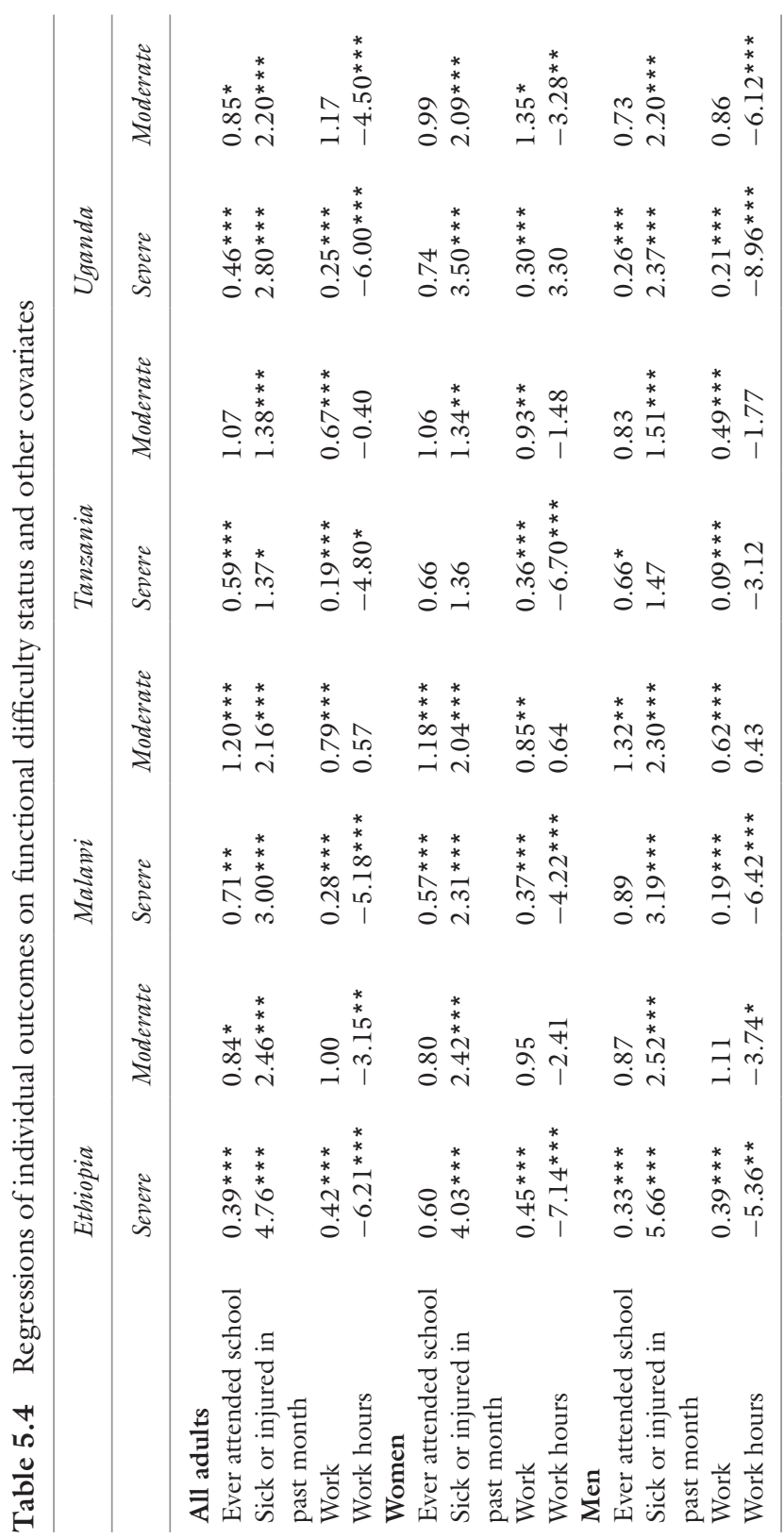

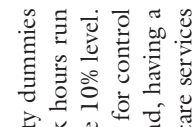

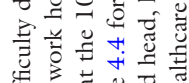

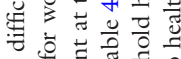

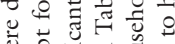

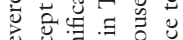

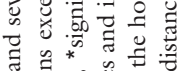

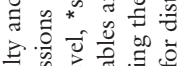

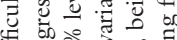
$\Leftrightarrow$ is i บ

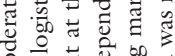

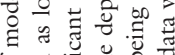

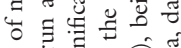

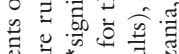

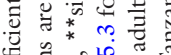

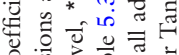

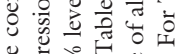

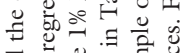

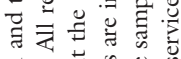

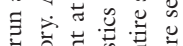
$\leadsto$ 苞 छ

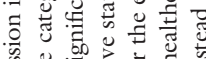

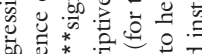

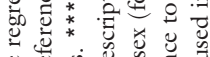
岕它岕的

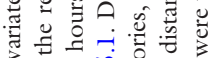
$\therefore \div$ in

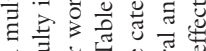

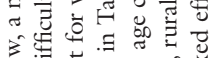

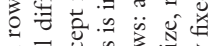

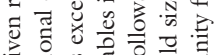
品过设

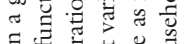

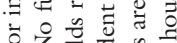

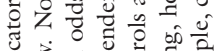

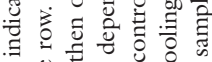

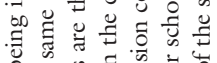

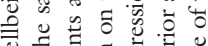

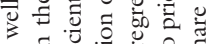

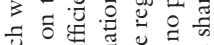
ษँّ

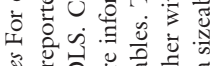

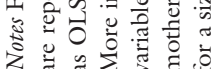


These results above largely hold in subsamples of women and men in the bottom two panels of Table 5.3. Comparing now women to men, women are less likely to have ever been to school, more likely to have been sick or injured recently and less likely to work, whatever the functional difficulty status.

Perhaps these results so far reflect to some extent cohort effects, with persons with functional difficulties being on average older and having less education. The association between functional difficulty and deprivations at the individual level is further considered through the regression model (5.4) of Box 3 controlling for various characteristics, including age. As shown in Table 5.4, results are quite consistent across countries. Moderate and severe difficulties are significantly associated with lower odds of ever attending school and higher odds of being sick or injured. For work, lower odds of working and lower hours of work are associated with severe difficulty in all countries. For instance, in Uganda, the odds of working for a person with a severe difficulty are 0.25 the odds of working of a person with no functional difficulty, everything else equal. Results are more mixed for moderate difficulty with a significant association with lower odds of working in Malawi and Tanzania, and significantly lower work hours in Ethiopia, Tanzania, and Uganda.

Similar regressions are run with the individual functional difficulty score in Table 5.5 instead of the severe and moderate difficulty binary variables. The functional difficulty score is consistently and significantly associated with worse individual wellbeing outcomes for all countryindicator pair except schooling in Malawi. For example, in Ethiopia, a $10 \%$ higher functional score is associated with a $32.7 \%$ lower probability of working.

Table 5.5 Regressions of individual outcomes on functional score and other covariates

\begin{tabular}{lrrrr}
\hline & Ethiopia & Malawi & Tanzania & \multicolumn{1}{c}{ Uganda } \\
\hline Ever attended school & $-4.13^{* * *}$ & 0.37 & $-1.59^{* * *}$ & $-3.35^{* * *}$ \\
Sick or injured in past month & $7.06^{* * *}$ & $7.37^{* * *}$ & $2.15^{* * *}$ & $5.69^{* * *}$ \\
Work & $-3.27^{* * *}$ & $-5.47^{* * *}$ & $-5.82^{* * *}$ & $-5.84^{* * *}$ \\
Work hours & $-36.08^{* * *}$ & $-11.65^{* *}$ & $-18.08^{* *}$ & $-37.48^{* * *}$ \\
\hline
\end{tabular}

Note The notes of Table 5.4 apply. The right hand side variable of interest for which the estimated coefficient is reported is the functional score. 


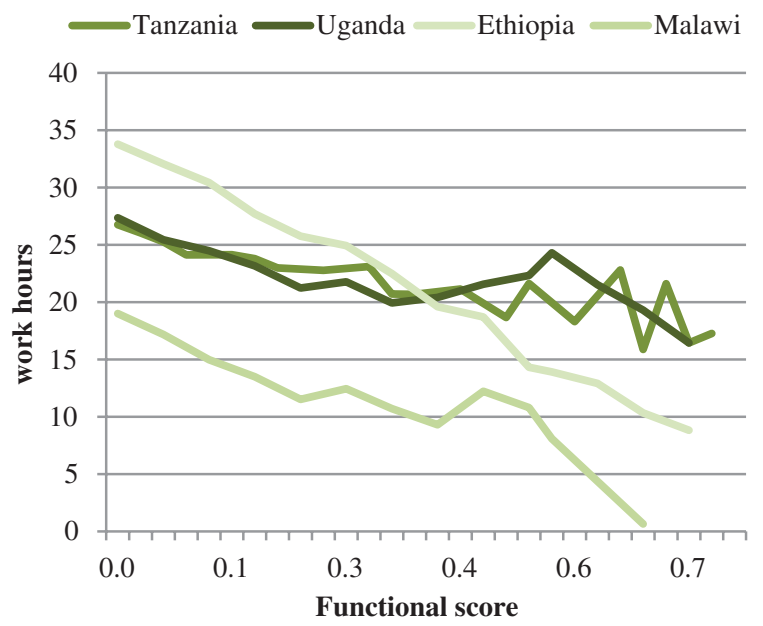

Fig. 5.1 Predicted work hours by functional score

Notes This is the predicted mean work hours by functional score among working adults using an OLS regression with control variables as follows: age categories, sex, being married, being the household head, having a mother with no prior schooling, household size and distance to healthcare services

Figure 5.1 gives the predicted value of work hours vs. the individual functional score, based on the regression model in Table 5.5. For all four countries, there is a negative relationship between work hours and functional score, which extends from low to high values of the functional score. It also applies to values of the functional score in the moderate difficulty range, for example from 0.05 to 0.10 . There is a gradient in work hours across severe, moderate, and no difficulty.

\subsubsection{Household Wellbeing}

Table 5.6 compares wellbeing outcomes of households with at least an adult with a severe or moderate difficulty to households with no functional difficulty. In all four countries, households with an adult with a moderate or severe functional difficulty tend to have worse living conditions or own fewer assets as reflected by a lower asset score. They are also more prone to economic insecurity with higher shares of food insecure households and households subject to a recent shock. 


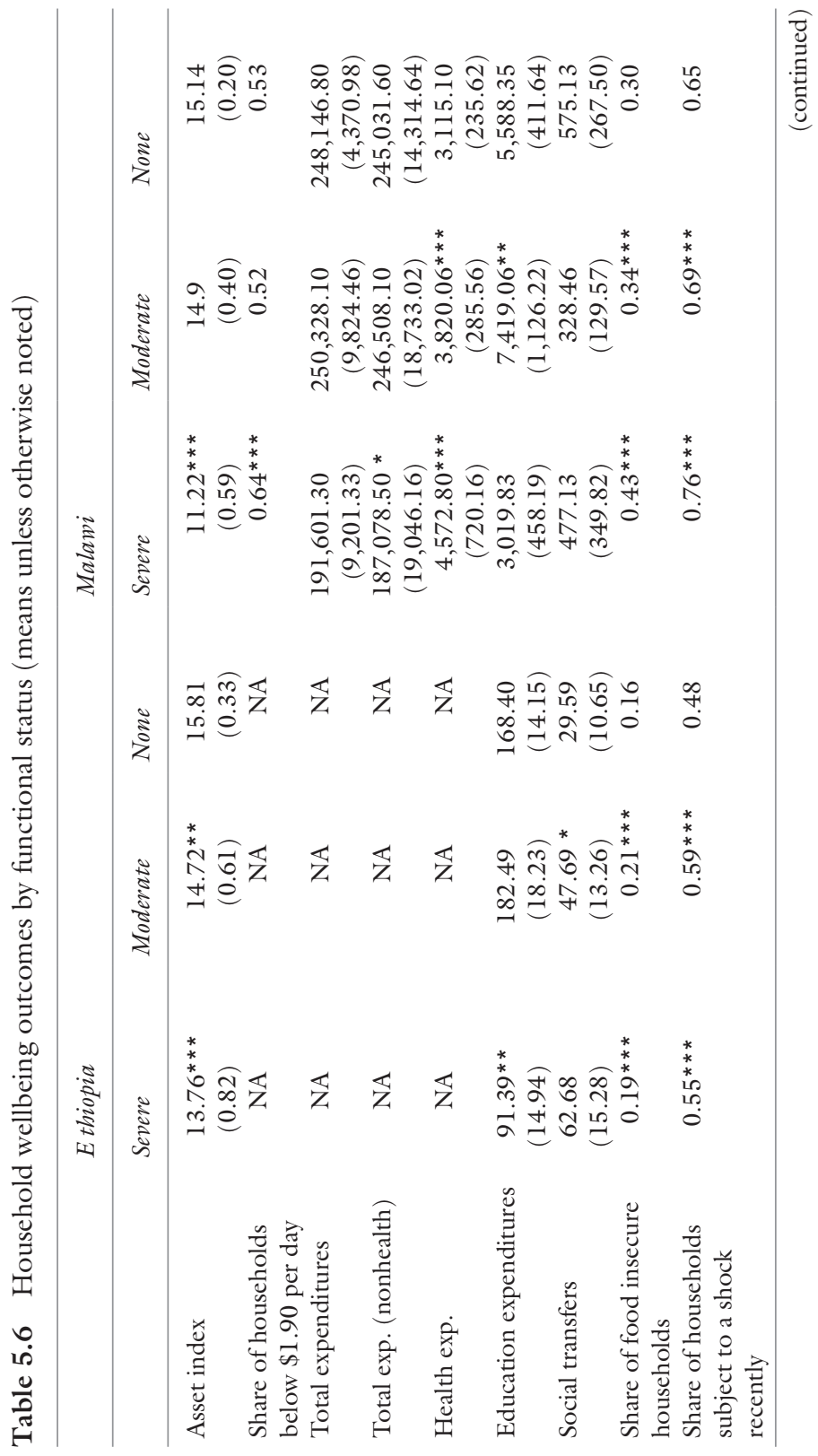




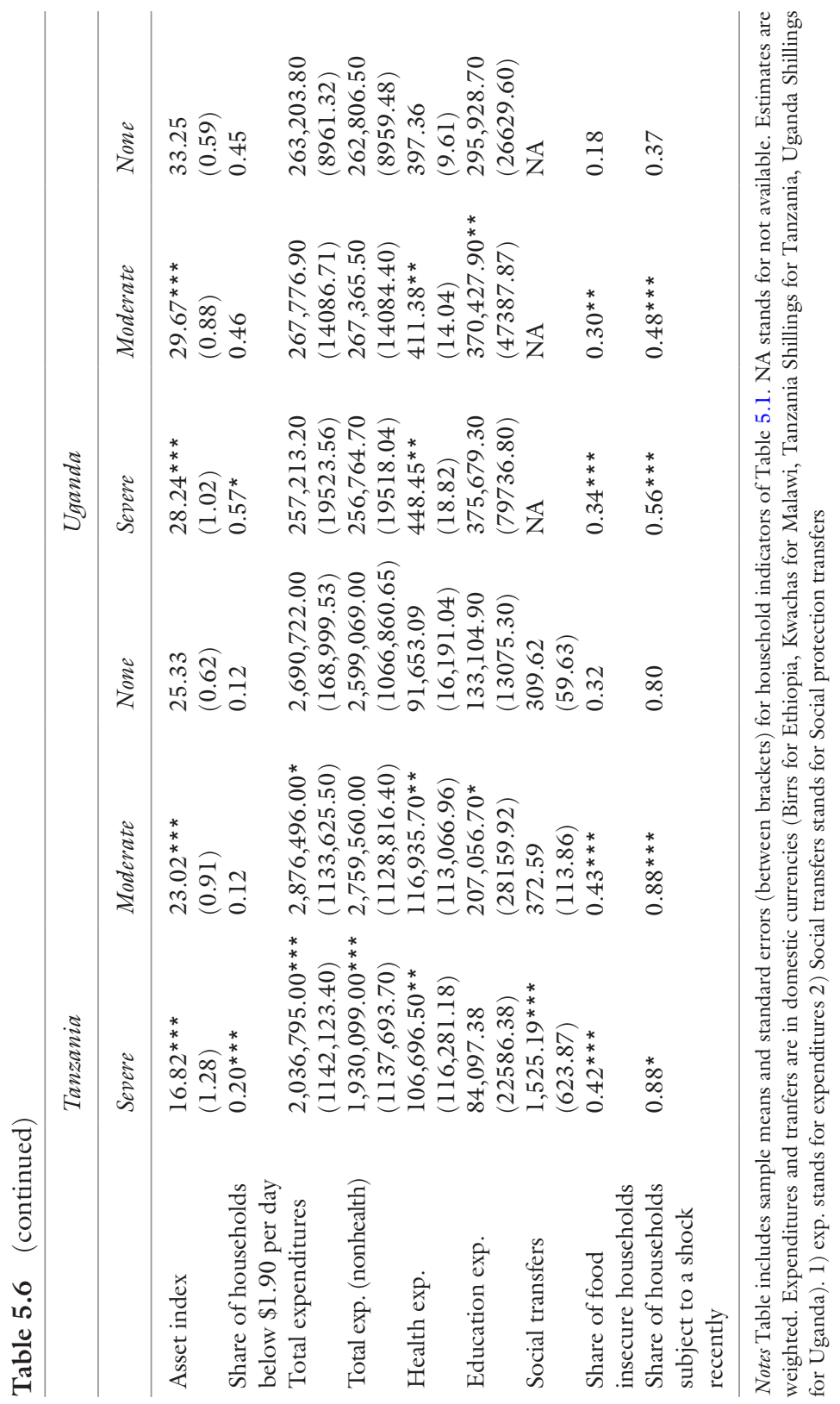


The poverty headcount using the $\$ 1.90$ a day poverty line is about 10 percentage point higher among households with severe functional difficulties in Malawi, Tanzania, and Uganda. No significant difference is found for households with moderate difficulties. Mean total expenditures and total nonhealth expenditures are not significantly different across groups except in Tanzania where they are significantly lower among households with severe difficulties. Households with functional difficulties incur significantly higher health expenditures than other households in Malawi and Tanzania, but not in Uganda. In Ethiopia, significantly lower educational expenditures are found, but not in other countries. Households with functional difficulties receive significantly higher social protection transfers in Tanzania, but not in Ethiopia and Malawi.

This association between household economic indicators and functional difficulties may be due to differences in household characteristics. Perhaps the lower education expenditures found in Ethiopia for households with a severe functional difficulty result from the older ages of household members when a household has a severe functional difficulty. The associations are analyzed further in Table 5.7 with multivariate regressions. It gives the estimated coefficient of the two variables that indicate if at least one adult in the household experiences a severe or moderate functional difficulty. The model includes as controls the household head and household characteristics described in Box 3 and Table 4.7.

In the four countries, households with functional difficulties, whether moderate or severe, are consistently more likely to be food insecure and to experience a shock. For instance, in Uganda, households with moderate or severe functional difficulties, respectively, have 1.3 or 1.8 higher odds of being subject to shocks than households without any functional difficulty.

For other household outcomes, results vary across countries. Having an adult with a functional difficulty in the household is significantly associated with lower asset ownership in Ethiopia and Tanzania, lower total expenditures in Tanzania, lower education expenditures in Ethiopia and Malawi and higher health expenditures in two out of three countries (Malawi and Tanzania). It is significantly correlated with higher social protection transfers in Ethiopia, Malawi, and Tanzania for moderate or severe functional difficulties.

Total expenditures do not differ across functional status in all countries, except for moderate functional difficulty in Malawi. This is consistent with Mitra et al. (2013), who, based on a bivariate analysis, find no significant difference in expenditures in 15 LMICs using WHS data, 


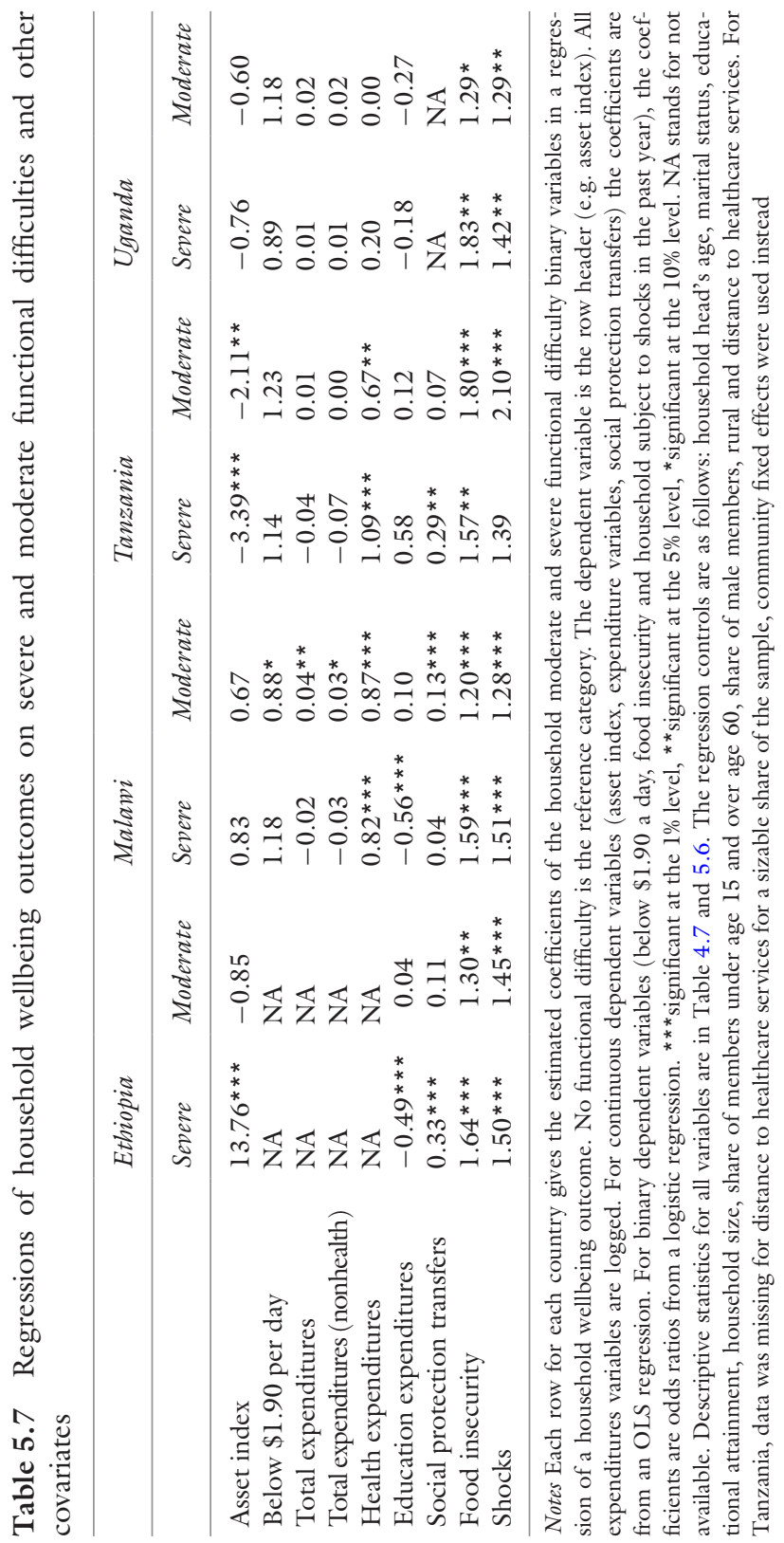


where the expenditures survey questions were few and not detailed. Using a very detailed expenditure questionnaire from the LSMS, no significant difference is found here either.

Some differences are found though for certain types of expenditures. Health expenditures information is available in three countries. Having a moderate or severe functional difficulty is associated with higher health expenditures in Malawi and Tanzania but not for Uganda. This result supports the hypothesis of conversion factors associated with functional difficulty as explained in Chapter 2. Households with functional difficulties have on average higher health expenditures in Malawi and Tanzania, which may make the conversion of income into wellbeing more challenging. In particular, higher health expenditures may crowd out other expenditures and indirectly make households more prone to worse living conditions, asset accumulation and food insecurity as shown earlier.

Significantly lower education expenditures are associated with a severe functional difficulty in Ethiopia and Malawi, but not in Tanzania and Uganda. This might suggest an allocation of expenditures away from education and toward health or other expenditures affected by the functional difficulty as found in Mitra et al. (2016) for Vietnam.

In the four countries, a consistent result is that having a moderate difficulty is less strongly associated with a household wellbeing deprivation than having a severe difficulty across all household wellbeing indicators. Nonetheless, households with a moderate difficulty are more often deprived, everything else held constant, than households with no functional difficulty especially with respect to food insecurity and shocks.

Similar regressions are run with the household functional difficulty score $^{15}$ in Table 5.8 instead of the severe and moderate difficulty binary variables in Table 5.7. The functional difficulty score is associated with worse household wellbeing outcomes for three to five wellbeing indicators by country. For instance, for a household in Ethiopia, a 10\% higher functional difficulty score is associated with $13.4 \%$ higher odds of having experienced a recent shock and $11.2 \%$ higher odds of being food insecure. It is also associated with education expenditures lower by 16.3 ETB (Ethiopian Birr) and social protection transfers higher by 10.2 ETB.

\subsubsection{Multidimensional Poverty}

Results of the multidimensional poverty analysis using Alkire and Foster (2011) and the dimensions, indicators and weights in Table 5.2 are first shown in the spider charts in Fig. 5.2, which gives the deprivation rates across functional difficulty status for each of the five dimensions. 
Table 5.8 Regressions of household wellbeing outcomes on functional score and other covariates

\begin{tabular}{lllll}
\hline & Ethiopia & Malawi & Tanzania & Uganda \\
\hline Asset index & -3.61 & -0.03 & $-13.1^{* * *}$ & $-6.70^{* *}$ \\
Below \$1.90 per day & NA & 1.08 & 1.28 & 2.53 \\
Total expenditures & NA & -0.03 & -0.05 & 0.00 \\
Total expenditures (nonhealth) & NA & -0.10 & -1.16 & -0.01 \\
Health expenditures & NA & $6.42^{* * *}$ & $4.81^{* * *}$ & 0.15 \\
Education expenditures & $-1.63^{* * *}$ & $-1.52^{* *}$ & $-1.63^{* * *}$ & -0.58 \\
Social protection transfers & $1.02^{* * *}$ & $1.05^{* * *}$ & 0.66 & 0.66 \\
Food insecurity & $1.12^{*}$ & $2.87^{* * *}$ & $2.04^{* * *}$ & $0.52^{* * *}$ \\
Shocks & $1.34^{* * *}$ & $2.11^{* * *}$ & $1.73^{* *}$ & $0.36^{*}$ \\
\hline
\end{tabular}

Notes Each row for each country gives the estimated coefficient of the household functional score in a regression of a household wellbeing outcome. Other notes on dependent and independent variables of Table 5.7 apply. NA stands for not available

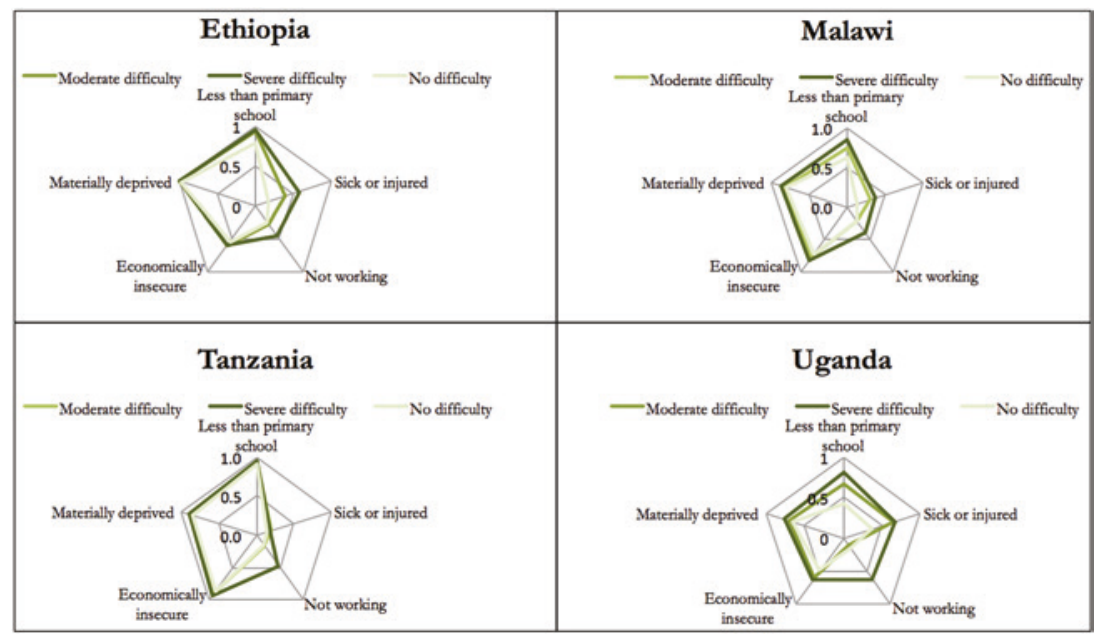

Fig. 5.2 Rates of deprivation by dimension and functional difficulty status. Note Deprivations using dimensions, thresholds and indicators described in Table 5.2 
The three lines, from dark to light green, connect the deprivation rates for persons with severe, moderate, or no difficulty, respectively. Unsurprisingly, the darker lines are on the outskirts of the lighter line for each country, showing higher deprivation rates for persons with functional difficulties. The gaps between the lines are larger for individual wellbeing dimensions (less than primary school, sick or injured and not working) than for household wellbeing dimensions (materially deprived and economically insecure). The gap between persons with moderate and no difficulty is smaller than the gap between persons with severe and no difficulty.

Results for multidimensional poverty measures are given in Fig. 5.3 and Appendix A4 for all adults. A higher headcount $(\mathrm{H})$ is found among persons with moderate or severe functional difficulties, and the difference across functional difficulty status is found to be statistically significant in all countries. More than eight in 10 adults with functional difficulties experience multidimensional poverty. Roughly, the difference in the multidimensional headcount ratio is around 20 and 10 percentage points in the four countries comparing, respectively, persons with severe and moderate difficulties to persons without any difficulty.

The average deprivation share (A), i.e. the share of dimensions in which the poor have deprivations, is significantly higher among persons with severe or moderate difficulty in all countries (Appendix A4). In other words, the poor with functional difficulties face more deprivations than the poor without any functional difficulty. Appendix A4 also presents the adjusted headcount ratio $\left(\mathrm{M}_{0}\right)$. The adjusted headcount ratio is found to be higher among persons with functional difficulties than persons without in all countries. The difference in the adjusted headcount ratio across functional difficulty status is the largest in Uganda; it is more than twice higher among persons with severe functional difficulties compared to persons without any difficulty. The gaps across functional difficulty status found in almost all dimensions of wellbeing earlier in Fig. 5.2 suggest that the gaps also found with multidimensional poverty measures are not sensitive to the dimension weights used in the analysis (Table 5.2).

Appendix A5 gives multidimensional poverty measures for sex and age subgroups. While women almost always have higher multidimensional poverty than men whatever the functional difficulty status, women with functional difficulties also have higher $\mathrm{H}, \mathrm{A}$ and $\mathrm{M}_{0}$ than women without difficulties. It shows that women with functional difficulties experience 


\section{Multidimensional Poverty Headcount}

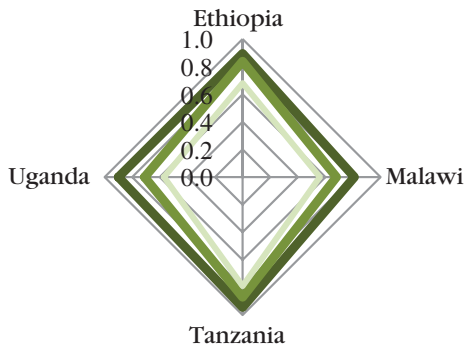

Severe difficulty

Moderate difficulty

No difficulty

\section{Average Deprivation Share}

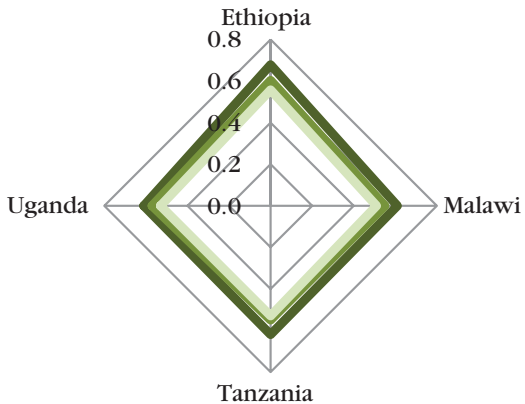

Severe difficulty

Moderate difficulty No difficulty

\section{Adjusted Multidimensional \\ Headcount}

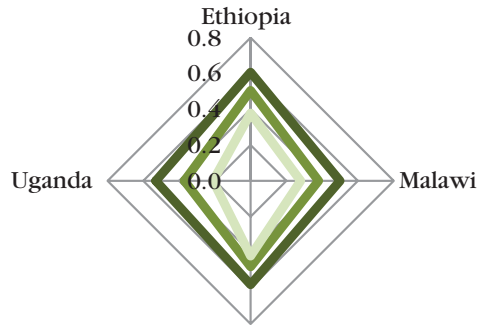

Severe difficulty

Moderate difficulty

Tanzania

Fig. 5.3 Multidimensional poverty and functional difficulty status 


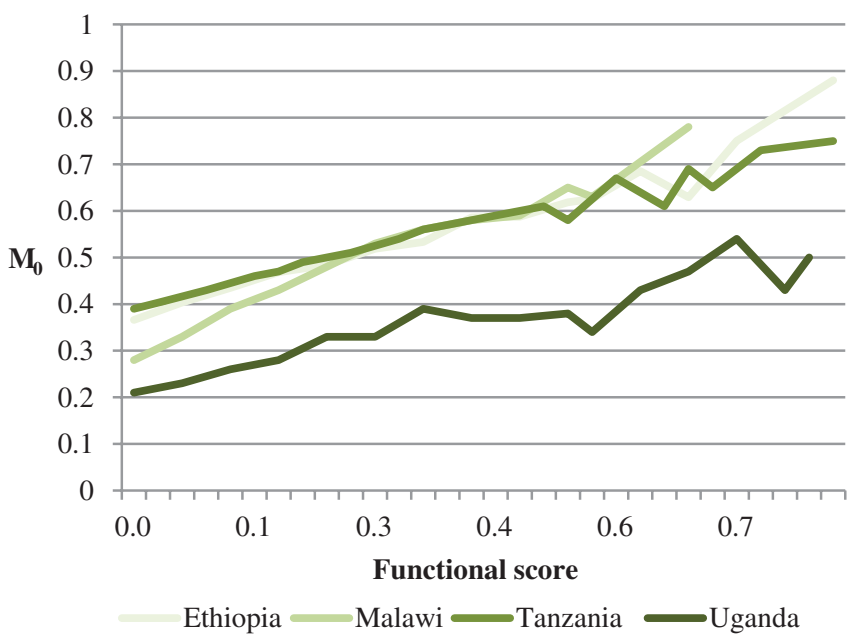

Fig. 5.4 Predicted multidimensional poverty adjusted headcount $\left(\mathrm{M}_{0}\right)$ by functional score. Note This is the mean adjusted multidimensional headcount by functional score using an OLS regression as in Box 3

a double disadvantage associated with gender and functional difficulty. This double disadvantage is, for instance, stark in Uganda where 96\% of women with severe functional difficulties are multidimensionally poor compared to $52 \%$ of men with no functional difficulty. By age group, the assessment is somewhat different. Among persons with no functional difficulty, being older than 50 is not always associated with being more often multidimensionally poor than those younger than 50 ; for $\mathrm{H}$, it is the case in Ethiopia and Malawi, but not in Tanzania and Uganda. However, having a functional difficulty is consistently associated with being more often multidimensionally poor within each age group.

Figure 5.4 gives the predicted $\mathrm{M}_{0}$ by functional score after adjusting for a number of covariates listed in Box 3 . In the four countries, there is a positive and steep gradient in the functional score. Appendix A6 gives the full results of the regression. The functional difficulty score is the covariate with the highest coefficient, above those of sex, age groups, marital status, mother's schooling, rural residence, and the distance to healthcare services. 


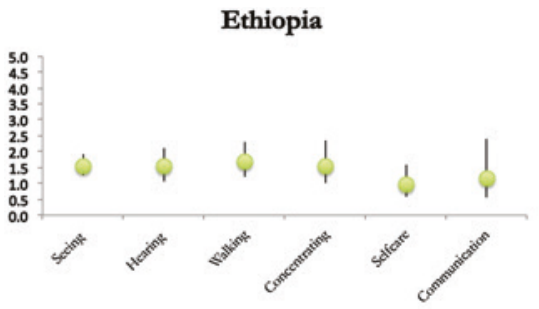

Tanzania

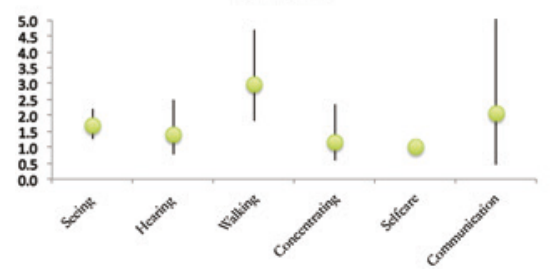

Malawi

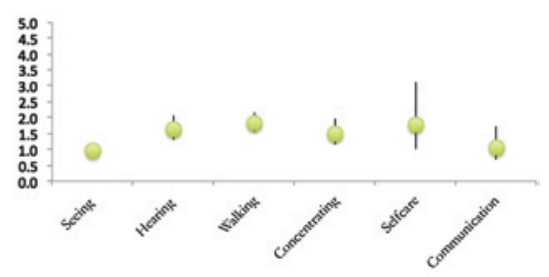

Uganda

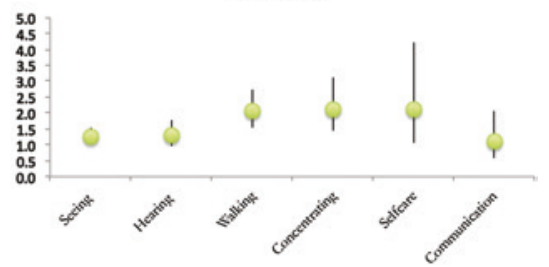

Fig. 5.5 Odds ratio of being multi-dimensionally poor by type of functional difficulty

\subsubsection{Type of Functional Limitation and Age of Onset}

Finally, Fig. 5.5 presents results of a logistic regression of the probability of being multidimensionally poor. It gives the odds ratio of being multidimensionally poor for each functional difficulty type among all adults. For instance, for seeing in Malawi, an odds ratio close to one indicates that having this difficulty is associated with odds of being multidimensionally poor that are similar to those of a person without such difficulty, everything else held constant. A lower bound of the confidence interval above one for the odds ratio indicates a higher likelihood of being multidimensionally poor associated with a functional difficulty type. Figure 5.5 shows that having a walking difficulty is associated with higher odds of being multidimensionally poor in all four countries, followed by having a concentrating difficulty in three countries and a seeing, hearing, or selfcare difficulty in two countries, and communication difficulty in no country.

While Fig. 5.5 is focused on multidimensional poverty, Appendix A7 considers in turn a deprivation in a domain (e.g., education, morbidity) and its association with the different functional disability types among all 
adults. Results are consistent with those in Fig. 5.5, with walking as the functional difficulty the most often associated with deprivations.

Finally, for Tanzania and Uganda, information is available on age at onset among persons with functional difficulties as shown earlier in Fig. 4.3. The model of Box 3 was used this time replacing moderate and severe functional difficulties with age at onset during working age years (15-49 years old) and age at onset during old age (50 and above). The sample was restricted to persons with functional difficulties. Results are not shown. Having an onset from birth to age 14 was the reference category. Among persons with functional limitations, no significant association was found between having an onset during working age or older years and having different odds of deprivation in turn for each wellbeing domain (e.g., education, morbidity) and for multidimensional poverty. The exception was for Tanzania, where having an onset during working age years was significantly associated with higher odds of being materially deprived.

\subsection{Conclusion: Summary and Implications}

The results in this chapter add to a small but growing quantitative literature on the association between disability and inequalities by using an internationally comparable disability measure and very detailed economic wellbeing information. Compared to earlier studies, it has indeed more detailed information on employment, household expenditures, and economic insecurity. I summarize below the main results of interest of this chapter and derive policy and research implications.

1. Results from both descriptive statistics and regressions indicate that functional difficulties, whether moderate or severe, are significant and large correlates of both individual and household wellbeing deprivations in Ethiopia, Malawi, Tanzania, and Uganda. This is found through an indicator-by-indicator analysis as well as through an assessment of multidimensional poverty, in descriptive and multivariate analyses. More than eight in ten persons with severe functional difficulties experience multidimensional poverty in Ethiopia, Malawi, Tanzania, and Uganda.

2. The association is found to be strong and consistent for several dimensions of wellbeing at both the individual (education, morbidity, work status) and the household levels (economic insecurity). 
The association seems stronger and more consistent than in earlier studies (e.g., Filmer 2008; Mitra et al. 2013; Trani et al. 2015).

These results support the inclusion of moderate and severe functional difficulties as potential correlates of deprivations in poverty monitoring, evaluation, and programmatic efforts in LMICs. It also supports a disaggregation by functional difficulty status of the indicators used to monitor the SDGs, in particular SDG \#1, which states as a goal the eradication of hunger and poverty in all its forms' (UNDP 2016).

The result on household-level economic insecurity is consistent with results from qualitative research that deprivations are not contained to the individual and are also a 'family affair' (Grech 2016). This result also implies that policies aimed to improve household wellbeing need to pay attention to functional difficulties. Indeed, despite the development of social protection programs in recent years in the four countries, deprivations in terms of material wellbeing and food insecurity are widespread, and disproportionately so among households with functional difficulties.

3. For some individual and household outcomes (job type, assets, total expenditures), results were not consistent across countries. In three countries, total expenditures do not differ across functional status, which is consistent with earlier results in the literature. Total expenditures may reflect additional expenditures associated with a functional difficulty (e.g., health, transportation and care expenditures).

4. This analysis also shows that not all persons with functional difficulties are poor; persons with disabilities are not always among the poorest of the poor. Some persons with functional difficulties do achieve levels of wellbeing comparable to persons with no difficulty.

5. The association between functional difficulties and deprivations was found for both severe and moderate functional difficulties, although it was typically larger and more often significant for the former. Moderate functional difficulties are also correlates of deprivations, and there is a severity gradient in the association between deprivations and functional difficulties, consistent with other findings in the literature (Banks et al. 2014).

6. Analyses should try to incorporate the degree of functional difficulties through several categories (e.g., moderate, severe) or a 
score. Yet recommendations of the use of the Washington Group questions focus on the group with severe functional difficulties. Analyses that focus on severe functional difficulties leave out persons with moderate functional difficulties who are also at risk of poverty.

7. In addition to functional difficulties, older ages and being female are also correlated with deprivations. This makes older persons with functional difficulties and women with functional difficulties more likely to be multidimensionally poor. These results underscore the importance of considering and addressing age and sex differences when formulating prevention and inclusion strategies with respect to functional status.

\section{Notes}

1. There was very limited research conducted prior to 2000 as shown in Elwan (1999). The gray literature has been growing but is included primarily if it pertains to the four countries under study or other countries in Africa.

2. Examples of such qualitative studies include Grech (2015); Eide and Ingstad (2011). For reviews of the literature, see Grech and Soldatic (2016).

3. Eide and Kamaleri (2010) (Lesotho), Eide et al. (2003b) (Namibia), Loeb and Eide (2004) (Malawi), Eide and Kamaleri (2009) (Mozambique), Palmer et al. (2010) (Vietnam), World Bank (2009) (India).

4. Evidence is offered in the following studies, among others: Eide and Mmatli (2016) (Botswana), Loeb and Eide (2004) (Malawi), GayleGeddes (2015) (Jamaica), Hoogeveen (2005) (Uganda), Loeb et al. (2008) (South Africa), Mete (2008) (Eastern Europe), Mitra et al. (2013) (15 LMICs), Mont and Cuong (2011) (Vietnam), Rischewski et al. (2008) (Rwanda), Trani and Loeb (2010) (Afghanistan and Zambia), World Bank (2009) (India), WHO-World Bank 2011 (59 countries).

5. Eide and Jele (2011) (Swaziland), Eide and Kamaleri (2010) (Lesotho), Eide and Mmatli (2016) (Botswana), Gayle-Geddes (2015) (Jamaica), Hoogeveen (2005) (Uganda), Mete (2008) and Mussida and Sciulli (2016) (Eastern Europe), Mitra (2008) and NDSD (2015) (South Africa), Mitra and Sambamoorthi (2008) (India), Payne et al. (2013) (Malawi), World Bank (2009) (India), Trani and Loeb (2010) (Afghanistan and Zambia), UNESCAP (2016) (Asia), WHO-World Bank (2011) (59 countries). 
6. One can get a sense of the variety of methods under use by reading Filmer (2008), Mitra and Sambamoorthi (2008) and Trani and Loeb (2010).

7. Each variable is weighted using the corresponding eigenvector for the first principal component, found by a principal component analysis.

8. Health expenditures include those associated with inpatient and outpatient contacts, nonprescription medication and medical equipment.

9. Education expenditures are collected at the individual level for all household members who attend school and then aggregated at the household level.

10. Mitra, Palmer et al. (2017) offer a recent review of this literature.

11. A shock is an unexpected negative event. The list of shocks covered in the survey is in Table 5.1.

12. Descriptive statistics are in Table 4.4.

13. Descriptive statistics are in Table 4.7.

14. Results in Sect. 4 on prevalence illustrate this for gender and rural residence.

15. The household functional difficulty score is the highest functional difficulty score among adults aged 15 and above in the household.

\section{REFERENCES}

Adioetomo, M., Mont, D., \& Irwanto. (2014). Persons with disabilities in Indonesia: Empirical facts and implications for social protection policies. Lembaga Demografi. http://www.tnp2k.go.id/images/uploads/downloads/ Disabilities\%20report\%20Final\%20sept2014\%20(1).pdf. Accessed l March 2017. Alkire, S., \& Foster, J. (2011). Counting and multidimensional poverty measurement. Journal of Public Economics, 95, 476-487.

Alkire, S., \& Santos, M. E. (2010). Acute multidimensional poverty: A new index for developing countries. Oxford: Oxford Poverty and Human Development Initiative.

Alkire, S., \& Santos, M. E. (2014). Measuring acute poverty in the developing world: Robustness and scope of the multidimensional poverty index. World Development, 59, 251-274.

Baldwin, M. L., \& Johnson, W. G. (2005). A critical review of studies of discrimination against workers with disabilities. In W. M. Rodgers III (Ed.), Handbook on the economics of discrimination (pp. 119-160). Cheltenham, MD: Edward-Elgar Publishing.

Banks, M. L., \& Polack S. (2014). The economic costs of exclusion and gains of inclusion of people with disabilities: Evidence from low-and middle-income countries. International Center for Evidence in Disability.

Brucker, D. L., Mitra, S., Chaitoo, N., \& Mauro, J. (2015). More likely to be poor whatever the measure: Working age persons with disabilities in the United States. Social Science Quarterly, 96(1), 273-296. 
Eide, A. H., \& Ingstad, B. (Eds.). (2011). Disability and poverty: A global challenge. Bristol: Policy Press.

Eide A. H., \& Jele, B. (2011). Living conditions among people with disabilities in Swaziland. A National, Representative Study. SINTEF A 20047. Oslo: SINTEF Technology \& Society.

Eide, A., \& Kamaleri, Y. (2009). Living conditions among people with disabilities in Mozambique. A national representative study. Oslo: SINTEF Health Research.

Eide, A. H., \& Kamaleri, Y. (2010). Living conditions among people with disability in Lesotho. Oslo: SINTEF Health Research.

Eide, A. H., \& Mmatli, T. (2016). Living conditions among people with disability in Botswana. Oslo: SINTEF Health Research.

Eide, A., Nhiwathiwa, S., Muderedzi, J., \& Loeb M. (2003a). Living conditions among people with activity limitations in Zimbabwe. A regional representative survey. Oslo: SINTEF Health Research.

Eide, A., van Rooy, G., \& Loeb, M. (2003b). Living Conditions among People with Activity Limitations in Namibia. A national representative survey. Oslo: SINTEF Health Research.

Elwan, A. (1999). Poverty and disability: A survey of the literature, (Social protection discussion paper series, No. 9932). Washington, DC: The World Bank.

Filmer, D. (2008). Disability, poverty and schooling in developing countries: Results from 14 household surveys. The World Bank Economic Review, 22(1), $141-163$.

Filmer, D., \& Pritchett, L. H. (2001). Estimating wealth effects without expenditure data-or tears: An application to educational enrollments in states of India. Demography, 38(1), 115-132.

Gayle-Geddes, A. (2015). Disability and inequality: Socioeconomic imperatives and public policy in Jamaica. London: Palgrave MacMillan.

Grammenos, S. (2013). European comparative data on Europe 2020 \& people with disabilities. Final report on behalf of the Academic Network of European Disability Experts (ANED).

Grech, S. (2015). Disability and poverty in the global South. Renegotiating development in Guatemala. London: Palgrave Macmillan.

Grech, S. (2016). Disability and poverty: Complex interactions and critical reframings. In Grech, S. and Soldatic, K. (eds) (2016). Disability in the Global South: the Critical Handbook, pp. 217-236 International Perspectives on Social Policy, Administration and Practice. Switzerland: Springer.

Grech, S., \& Soldatic, K. (Eds.). (2016). Disability in the global south: The critical handbook. International perspectives on social policy, administration and practice. Cham: Springer.

Groce, N., Kett, M., Lang, R., \& Trani, J. F. (2011). Disability and poverty: The need for a more nuanced understanding of implications for development policy and practice. Third World Quarterly, 32(8), 1493-1513. 
Hoogeveen, J. G. (2005). Measuring welfare for small but vulnerable groups: Poverty and disability in Uganda. Journal of African Economies, 14(4), 603631.

Loeb, M., \& Eide, A. (2004). Living conditions among people with activity limitations in Malawi. Oslo: SINTEF Health Research.

Loeb, M., Eide, A., Jelsma, J., Toni, M., \& Maart, S. (2008). Poverty and disability in eastern and western cape provinces, South Africa. Disability and Society, 23(4), 311-321.

Mete, C. (Ed.). (2008). Economic implications of chronic illness and disability in Eastern Europe and the former Soviet Union. Washington, DC: World Bank.

Mitra, S. (2008). The recent decline in the employment of persons with disabilities in South Africa, 1998-2006. South African Journal of Economics, 76(3), $480-492$.

Mitra, S., \& Sambamoorthi, U. (2008). Disability and the rural labor market in India: Evidence for males in Tamil Nadu. World Development, 36(5), 934952.

Mitra, S., Posarac, A., \& Vick, B. (2013). Disability and poverty in developing countries: A multidimensional study. World Development, 41, 1-18.

Mitra, S., Palmer, M., Mont, D., \& Groce, N. (2016). Can households cope with health shocks in Vietnam? Health Economics, 25(7), 888-907.

Mitra, S., Palmer, M., Kim, H., Mont, D., \& Groce, N. (2017). Extra costs of living with a disability: A review and agenda for future research.Disability and Health. DOI: http://dx.doi.org/10.1016/j.dhjo.2017.04.007.

Mizunoya, S., \& Mitra, S. (2013). Is there a disability gap in employment rates in developing countries? World Development, 42, 28-43.

Mizunoya, S., Mitra, S., \& Yamasaki, I. (2016). Towards inclusive education: The impact of disability on school attendance in developing countries. Innocenti (Working Paper No.2016-03). Florence: UNICEF Office of Research.

Mont, D., \& Cuong, N. (2011). Disability and poverty in Vietnam. World Bank Economic Review, 25(2), 323-359.

Mussida, C., \& Sciulli, D. (2016). Disability and employment across Central and Eastern European countries. IZA Journal of Labor \& Development, 5, 4.

NDSD. (2015) Elements of the financial and economic costs of disability to households in South Africa: A pilot study. Pretoria: National Department of Social Development, Republic of South Africa,

Palmer, M., Thuy, N., Quyen, Q., Duy, D., Huynh, H., \& Berry, H. (2010). Disability measures as an indicator of poverty: A case study from Vietnam. Journal of International Development. http://dx.doi.org/10.1002/ jid.1715.

Payne, C. F., Mkandawire, J., \& Kohler, H.-P. (2013). Disability transitions and health expectancies among adults 45 years and older in Malawi: A cohortbased model. PLoS Medicine, 10(5), el001435. doi:10.1371/journal. pmed.1001435. 
Rischewski, D., Kuper, H., Atijosan, O., Simms, V., Jofret-Bonet, M., Foster, A., et al. (2008). Poverty and musculoskeletal impairment in Rwanda. Transactions of the Royal Society of Tropical Medicine and Hygiene, 102, 608-617.

She, P., \& Livermore, G. (2009). Long-term poverty and disability among working-age adults. Journal of Disability Policy Studies, 19(4), 244-256.

Stiglitz, J. E., Sen, A. K., \& Fitoussi, J. P. (2009). Report by the commission on the measurement of economic performance and social progress. Paris: Commission on the Measurement of Economic Performance and Social Progress. Available at www.stiglitz-sen-fitoussi.fr/en/index.htm.

Trani, J., \& Loeb, M. (2010). Poverty and disability: a vicious circle? Evidence from Afghanistan and Zambia.Journal of International Development, 24(1), pp. S19-S52.

Trani, J.F., \& Canning, T.I.. (2013). Child poverty in an emergency and conflict context: A multidimensional profile andan identification of the poorest children in Western Darfur. World Development, 48, 48-70.

Trani, J., Bakhshi, P., Myer Tlapek, S., Lopez, D., \& Gall, F. (2015). Disability and poverty in Morocco and Tunisia: A multidimensional approach. Journal of Human Development and Capabilities, 16(4), 518-548.

Trani, J., Kuhlberg, J., Cannings, T., \& Chakkal, D. (2016). Multidimensional poverty in Afghanistan: Who are the poorest of the poor? Oxford Development Studies. doi:10.1080/13600818.2016.1160042.

UNDP. (2016). Sustainable development goals. United Nations Development Programme. Available: http://www.undp.org/content/undp/en/home/ sustainable-development-goals.html. Accessed August 20, 2016.

UNESCAP. (2016). Disability at a glance 2015. Accessed March 3, 2017 http://www.unescap.org/sites/default/files/SDD\%20Disability\%20 Glance\%202015_Final.pdf.

WHO-World Bank. (2011). World report on disability. Geneva: World Health Organization.

World Bank. (2009). People with disabilities in India: From commitments to outcomes. Washington, DC: World Bank. 
Open Access This chapter is licensed under the terms of the Creative Commons Attribution 4.0 International License (http://creativecommons.org/licenses/ by $/ 4.0 /$ ), which permits use, sharing, adaptation, distribution and reproduction in any medium or format, as long as you give appropriate credit to the original author(s) and the source, provide a link to the Creative Commons license and indicate if changes were made.

The images or other third party material in this chapter are included in the chapter's Creative Commons license, unless indicated otherwise in a credit line to the material. If material is not included in the chapter's Creative Commons license and your intended use is not permitted by statutory regulation or exceeds the permitted use, you will need to obtain permission directly from the copyright holder.

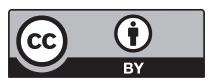

